\title{
Lesson Experiment Cycles: Examining Factors that Affect Prospective Teachers' Learning of Area Measurement
}

\author{
Michelle Chamberlin ${ }^{1 *}$ (D) \\ ${ }^{1}$ University of Wyoming, USA \\ *Corresponding Author: mchambe5@uwyo.edu \\ Citation: Chamberlin, M. (2022). Lesson Experiment Cycles: Examining Factors that Affect Prospective Teachers' Learning of Area Measurement. \\ International Electronic Journal of Mathematics Education, 17(1), em0665. https://doi.org/10.29333/iejme/11469

\begin{abstract}
ARTICLE INFO
Received: 4 May 2021

Accepted: 31 Oct. 2021

ABSTRACT

For teachers to provide students with meaningful instruction in area measurement, teachers need robust understandings of area. Here, I describe two cycles of a lesson experiment used to investigate prospective teachers' understandings of area units in an undergraduate mathematics class. For each cycle, I collected and analyzed the prospective teachers' written work and videotaped class discussions. The first cycle yielded a learning trajectory for helping prospective teachers better understand area units, which led to more teachers attaining the lesson goals in the second cycle. The paper articulates these classroom lessons and the lesson experiment process for fellow mathematics instructors and teacher educators.
\end{abstract}

Keywords: lesson experiment, prospective teachers, area measurement, undergraduate mathematics classes, teacher preparation

\section{INTRODUCTION}

Area measurement is a significant concept in school mathematics due to its many physical applications. As such, it is mandated in the curriculum guidelines for nearly all countries. Furthermore, area models are frequently used in curriculum and standards documents to illustrate many topics in number and arithmetic operations, e.g., multiplication and division, associative and distributive properties, and operations with rational numbers. To develop deep conceptual understandings of area measurement and area models, students need meaningful instructional experiences over time (e.g., Sarama \& Clements, 2009). For teachers to provide such experiences, they too need a robust understanding of area measurement. However, it has been shown internationally that teachers often experience some of the same challenges with area as students of ages 6-18 (e.g., Baturo \& Nason, 1996; Berenson et al., 1997; Browning et al., 2014; Livy et al., 2012; Tatto et al., 2012). These challenges include procedural, formulaic-based perceptions of area; confusions between length and area attributes; and misconceptions concerning area units.

In this paper, I focus on a particular challenge we found elementary prospective teachers (PSTs) experience with area measurement. In particular, I describe a lesson experiment used to investigate and enhance PSTs' understandings of area units. In a lesson experiment, a teacher-researcher tests hypotheses about cause-and-effect relationships between teaching and learning (Hiebert et al., 2003). The intent is to address, "What did students learn during the lesson, and how and why did instruction impact such learning?" (Hiebert et al., 2007, p. 48). The purpose of this paper is to present classroom lessons learned about supporting PSTs with understanding area measurement and area units. A secondary purpose is to share the lesson experiment process with fellow mathematics instructors and teacher educators in various contexts and settings, including grades K-12 (ages 6-18 years) and post-secondary settings.

\section{PROSPECTIVE TEACHER'S UNDERSTANDINGS OF AREA MEASUREMENT}

Area is typically defined in school mathematics and in teacher preparation programs as the amount of two-dimensional space contained within a closed region (Conference Board of Mathematical Sciences [CBMS], 2012; National Governors Association Center for Best Practices [NGA Center] \& Council of Chief State School Officers [CCSSO], 2010; Stephan \& Clements, 2003; Van de Walle, 2007). To directly measure area, one calculates the number of area units that cover the region without gaps or overlaps (CBMS, 2012; NGA Center \& CCSSO, 2010; Sowder et al., 2014; Van de Walle, 2007). Conventionally, we use square units to measure area (Reynolds \& Wheatley, 1996). While various two-dimensional shapes may be used as an area unit, squares have significant advantages. First, squares are easy to make congruent for equivalent units, and they tessellate the plane. Second, it is easier to quantify partial units of squares than other shapes due to the uniformity of squares (equal side lengths and angles). Finally, 
squares structure an area as an array of rows and columns so one may efficiently calculate the number of square units within any rectangular region by taking the length times the width.

PSTs' challenges with area measurement may be organized around three themes: Over-reliance on formulaic approaches, weak conceptual understandings of the attribute of area, and difficulties with area units. First, various sources have established that PSTs often rely on procedural and formulaic approaches for area measurement (e.g., Berenson et al., 1997; Browning et al., 2014). While such rule-based approaches may enable PSTs to determine the area of simple shapes using memorized formulas, many PSTs are unable to adapt these formulas when confronted with more complex figures or dimensions (Baturo \& Nason, 1996; Bilir, 2018; Chamberlin \& Candelaria, 2018; Simon \& Blume, 1994; Tatto et al., 2012). As Baturo and Nason (1996) explain, "the students' understanding of area measurement was rule-dominated but this knowledge was ineffective because the rules... lacked any meaning for the students" (p. 257). Second, PSTs' challenges with area measurement often relate to their perceptions of area as an attribute. Rather than seeing area as the amount of two-dimensional space contained within a closed region, they may define area as length times width, using a procedural explanation to describe area (Livy et al., 2012; Tierney et al., 1990). In addition, PSTs often confuse linear measurements with area measurements, for example not understanding the relationship between area and perimeter (Livy et al., 2012; Reinke, 1997) or using linear features of shapes to incorrectly rank shapes by area (Chamberlin \& Candelaria, 2018; Tierney et al., 1990). Third, PSTs' challenges with area measurement are often related to confusion about area units. Baturo and Nason (1996) note that our educational and conventional practice is to measure area not by quantifying the number of area units that cover a shape, but by obtaining measures of length and using them in formulas. Thus, students have very few educational experiences with actual area units and often fail to view area units as unit squares (Chamberlin \& Candelaria, 2018; Simon \& Blume, 1994). This leads to PSTs misappropriating linear units for area units (Baturo \& Nason, 1996; Tierney et al., 1990), struggling to understand how linear units generate area units (Baturo \& Nason, 1996; Chamberlin \& Candelaria, 2018; Simon \& Blume, 1994), and failing to appreciate the affordances of using unit squares for area units (Chamberlin \& Candelaria, 2018).

Failing to realize the affordances of square units was first recognized with elementary students by Lehrer and his colleagues when they conducted a 3-year study of teaching and learning geometry in first through third grade classrooms (Lehrer et al., 1998a, 1998b). Part of their work examined the preferences of elementary students in selecting shapes for area units. When asked to measure the area of a given region, the elementary students tended to treat the boundaries of such regions as absolute (not wanting the area units to cross the boundaries), known as boundedness. As a result, the students typically selected area units that resembled the particular region being measured (resemblance), even when such area units failed to be congruent or to tessellate the plane. For example, when one teacher asked her second grade students to measure the 'amount of space' covered by each of their hands, they selected area units such as beans because they resembled the contour of a hand and would align with the boundaries of their hands even though the beans were not all the same size or shape and left gaps between their repetitions. Challenges with resemblance and boundedness had not been reported with PSTs until we witnessed such dilemmas in a lesson with PSTs (Chamberlin \& Candelaria, 2018). We collected data from ten PSTs on the following post-test item: Describe the pros and cons of using a circle, a square, and an isosceles trapezoid as a unit for measuring area. Across all three shapes, seven PSTs strongly desired a resemblance between the shape being measured and the shape of the area unit as well as a need for boundedness (e.g., preferring circle area units to measure regions with curved edges and square area units to measure rectangular regions). The PSTs expressed concern that spaces would remain when using a unit that did not align with the edge of the measured region.

Encouragingly, educators have found PSTs' challenges with area measurement may be enhanced in content courses during their teacher education programs (Chamberlin \& Candelaria, 2018; Runnalls \& Hong, 2019; Simon \& Blume, 1994; Tierney et al., 1990). Commonalities amongst these instructional efforts are evident. They all emphasized area from a conceptual standpoint and implemented non-standard, non-formulaic area activities. The PSTs engaged in meaningful discussions about area and its measurement with their peers and instructor. Finally, the instructors clearly articulated their learning goals, engaged in on-going analyses of the PSTs' thinking, and made instructional decisions in response to PSTs' developing understandings. In our content courses for PSTs, we too have witnessed PSTs' challenges with area measurement. One area in particular, understanding the shape of area units and their affordances, peaked my interest as I did not find any other literature addressing this dilemma with PSTs. Due to our prior findings about PSTs' views on area units and the potential for instruction that incorporates the qualities noted above, I decided to undertake a lesson experiment to investigate and attempt to enhance PSTs' understandings of area units.

\section{LESSON EXPERIMENTS}

Lesson experiments entail collecting artifacts of students' thinking during pivotal moments of a lesson so that the instructor may reflect before, during, and after about how the instruction affected students' understandings (Hiebert et al., 2007). The experiment is applied to an instructional episode such as a task, a full lesson, or a sequence of lessons. It is composed of four steps akin to teacher as researcher, reflective practice, and disciplined inquiry.

The first step consists of explicating the learning goals as well as hypotheses of how instruction may support those goals, both of which then inform the planning of the lesson. The learning goals should articulate the essential knowledge, skills, and dispositions that the teacher wishes the students to develop (Jansen et al., 2009). They need to be well-specified and documented. Without specificity, they lack criteria against which to identify the types of evidence needed to determine if the learning goals have been met and to suggest interventions for supporting learners in achieving them. Without being documented in tangible products, such as lesson plans, the ability to evaluate them during instructional improvement activities is hindered. In sum, "targeted and shared learning goals support incremental, empirical knowledge-building processes, regardless of their content" (Jansen et al., 2009, p. 526). Articulating hypotheses of how instruction may then support the learning goals moves the lesson from a planned 
learning experience for the students to a planned learning experience for the teacher as well. Specifically, the teacher can test their local theories about how they think learning might proceed against what actually occurs in the classroom. Finally, with both the learning goals and the hypotheses specified, instructional planning proceeds accordingly.

The second step entails assessing to what extent students achieve the learning goals by gathering during the lesson and analyzing afterwards evidence of students' thinking from videos, transcripts, written work, or verbal statements. This step requires identifying key moments in a lesson when students will be learning and planning ways to collect evidence of students' thinking in those moments. The collected evidence must reveal whether the learning goals were achieved, provide information about the students' thinking beyond surface behaviors and responses, and include all students. Specificity with the learning goals and hypotheses help with analyzing such data to determine whether and to what degree the students achieved the learning goals.

The third step consists of evaluating the hypotheses and if needed developing new hypotheses for why the lesson did or did not achieve the learning goals, e.g., focusing on the instructional events that facilitated students' responses in the gathered evidence. These hypotheses and their evaluation need to be detailed and specific enough to be tested in future teaching episodes. Furthermore, they should appeal to well-supported principles for teaching and learning and be expressed with a recognition of the complexity of teaching-learning situations. The fourth step entails using the hypotheses to revise the current or future lessons based on evidence gathered and analyzed in the previous steps. The intent of the revised lesson is to help all students achieve the learning goals even more so than in the first lesson.

Clearly, the lesson experiment process operates optimally when cycles may be used for the incremental improvement of teaching and learning. Jansen et al. (2009) refer to their cyclical work as empirical tinkering, i.e., making and testing small changes to a system. At the University of Delaware, they engage in empirical tinkering to improve their courses for prospective elementary teachers. Specifically, during one or more semesters, the associated faculty and doctoral students select a particular lesson or subset of lessons to study and improve. They develop detailed hypotheses about how a small change to an instructional task may better support the prospective teachers in achieving the associated lesson goal(s). Then, they gather data to determine its effect on the prospective teachers' thinking. This evidence is used to evaluate the educational change and to elaborate upon and refine the associated learning goal(s). "A critical component of studying changes in teaching is testing empirically whether the change to the lesson was an improvement" (Jansen et al., 2009, p. 529).

Lesson experiments shift an instructor's focus from teaching in the moment to including preparation and reflection outside the classroom. Hiebert et al. (2007) find promise in the approach as its steps are taken from the practice of classroom teachers, it melds the activity of teaching and research, it offers instructors the opportunity to gain knowledge for improving their own teaching over time, and it works with all types of learning goals and student levels. While Hiebert and his colleagues foremost recommend lesson experiments to help teachers learn from teaching, they also recommend the approach for university instructors and teacher educators. At the post-secondary level, the processes are the same but now the 'students' are the undergraduate students and/or the prospective teachers and the 'teacher' is the university instructor or teacher educator (e.g., Phelps \& Spitzer, 2012).

\section{PEDAGOGICAL SETTING AND LESSON EXPERIMENT PROCESS}

I am a mathematics teacher educator housed in the mathematics and statistics department at a mid-sized research university in a rocky mountain region of the United States. One of my primary roles is to instruct and coordinate three mathematics courses designed for our elementary education majors, pursuing certification for grades K-6 (students ages 6-12 years). The third of these courses, the geometry and measurement course, served as the setting for the present lesson experiment. It typically consists of 30-32 PSTs with 3-5\% freshmen, $15-30 \%$ sophomores, 30-40\% juniors, and $25-35 \%$ seniors. Male prospective teachers tend to make up $10-15 \%$ of the class. The PSTs' mathematical backgrounds range from high school algebra through calculus.

In this course, I completed two cycles of a lesson experiment during two different semesters while I was the instructor of record. My overarching research question asked, "What did the PSTs learn about area units, and how and why did instruction impact such learning?" My data collection entailed gathering all written mathematical work from the PSTs and videotaping all whole-class discussions of our lesson activities (step two of a lesson experiment). My analysis consisted of two phases, (1) determining the extent to which the learning goals were achieved and (2) evaluating the instruction for whether and how it supported the learning goals (step three of a lesson experiment). For Phase I, I used open coding (Strauss \& Corbin, 1998) to analyze the PSTs' responses on the written work, identifying themes and frequencies within the PSTs' responses. For the video-tape analysis, I transcribed each discussion. For Phase II, I noted instances in which the learning goals were attained by the PSTs and returned to the written work and transcripts to identify which lesson activities engendered such understandings. Next, I noted instances in which the learning goals were not attained or misconceptions remained. I again returned to the written work and transcripts to identify how the lesson activities may have failed to address such issues. These issues pointed to possible instructional improvements (step four of a lesson experiment). Within the description of each cycle below, I offer further details about the data analysis procedures to make more transparent the actual approaches used and to speak to the reliability of the research findings. In addition, the completion of two cycles of the lesson experiment lend credibility to the descriptions of the PSTs' understandings and the instructional revisions. 


\section{FIRST CYCLE OF THE LESSON EXPERIMENT}

\section{Step One: Learning Goals, Hypotheses, and Lesson Planning}

My learning goals for the first cycle were for the PSTs to understand that area is measured by calculating the number of squares that cover a two-dimensional closed region and appreciate the advantages of measuring area with square units (congruency, tessellation, and ease of partial units), letting go of boundedness and resemblance preferences. To address students' preferences for boundedness and resemblance, Lehrer et al. (2003) recommend asking students to measure the space covered by an irregular region, providing various shapes that may be used as area units. Accordingly, my instructional hypothesis was asking the PSTs to measure the area of an irregular region using area units of various shapes would enable them to deduce the advantages and disadvantages of such shapes. Thus, the 31 PSTs worked in groups on the activity in Figure 1 (the actual funky shape that students measured was much larger, approximately 4 inches by 5 inches). We then engaged in a whole-class discussion about their findings. Finally, all PSTs individually completed a formative assessment (see Figure 2).

\section{Class Activity: Considering Various Shapes for Area Units}

1. Use the provided rectangles to measure the area of the "Funky Shape".

2. Describe the advantages and/or disadvantages of using rectangles as a unit for area.

The PSTs then completed questions \#1 and \#2 each with trapezoids,

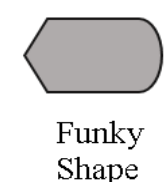

circles, squares, and a peanut-like shape.

Figure 1. Class activity completed by the PSTs at the beginning of the lesson experiment

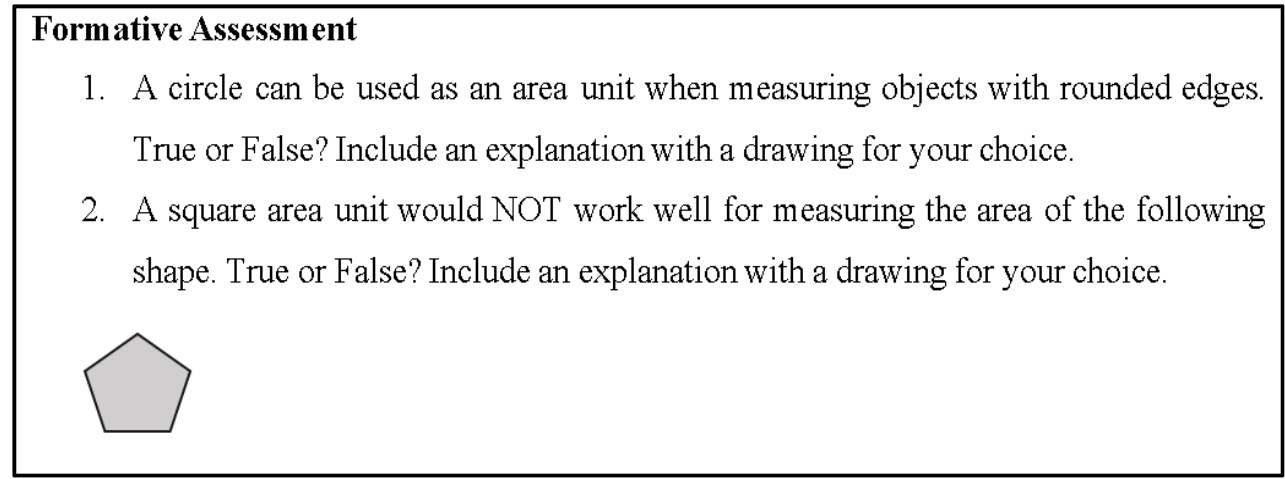

Figure 2. Formative assessment completed by the PSTs at the end of the lesson experiment

\section{Step Two: Evidence of PSTs' Thinking}

For evidence of the PSTs' thinking during and after the first-cycle lesson, I collected each group's written work on the class activity, video-taped the whole-class discussion, and collected from all 31 PSTs the formative assessment. To analyze the class activity data, I sorted the groups' written work by the area unit shape and then used open coding (Strauss \& Corbin, 1998) to examine how the PSTs covered the Funky Shape with the area unit as well as the advantages and disadvantages they described. I began the open coding process by reading through each group's write-up, assigning codes based on the meaning of the text. As I read additional write-ups, I repeated codes for similar meanings and adjusted other codes, returning to previous write-ups as needed. For example, with regard to how the groups covered the Funky Shape with the area unit, I had codes such as area unit arranged randomly with efforts to minimize gaps, tessellated area units but with different orientations along the different edges, utilized partial units, etc. With regard to advantages and disadvantages given, I had codes such as area units do/do not fit together, area units do/do not align with edge of Funky Shape, easy/hard to determine partial units, etc. Through this analysis, I was able to identify the themes within the groups' write-ups, the frequency of those themes, and the specific groups corresponding with each theme. Then, I noticed many parallels between the themes for the area units that do not tessellate (e.g., the circles and peanut shapes) and those that do tessellate (e.g., the rectangles, squares, and trapezoids). Thus, I then prepared a written explanation of the PSTs' mathematical understandings with regard to area units as revealed on the class activity in two sections: one section for non-tessellating area units and one section for tessellating area units.

For the video-tape analysis, I began by viewing the videotapes, simultaneously transcribing the discussion. Then, I added a column next to the transcript, and as I read and re-read through the transcript, I made note in this new column of the mathematical ideas that emerged in the discussion. Finally, I prepared a written summary of the whole-class discussion and the corresponding ideas about area units that arose.

For the Formative Assessment, I analyzed each question separately (\#1 and \#2) but used the same process for both. Similar to the class activity analysis, I used open coding to examine the PSTs' written explanations as well as their associated drawings. With 
regard to the PSTs' written explanations, I had codes such as the area unit does/does not leave gaps, easy to take partial units, etc. With regard to the PSTs' drawings, I had codes such as shows partial units, tessellates the area unit with the same orientation throughout, using one large square to edge of boundary, etc. Again, through such analysis, I was able to identify the themes within the students' explanations and drawings, the frequency of those themes, and the specific students corresponding with each theme. This information then enabled me to prepare a write-up describing the students' understandings and misunderstandings with regard to area units on the Formative Assessment.

On the class activity, the PSTs worked with the non-tessellating area units in similar ways (the peanut and circle) and then the tessellating area units in other ways (the square, rectangle, and trapezoid). For the non-tessellating area units, all groups randomly placed the area units as close together as possible over the Funky Shape, typically keeping the area units within the boundary. Then, they filled in the remaining gaps with partial units. The PSTs explained that the peanuts and circles were difficult for covering the Funky Shape, did not "fit together", and left gaps. For the tessellating area units, the PSTs typically began by placing a whole area unit next to one edge of the Funky Shape. Then, they repeated the area unit with the same orientation until doing so would cause the area unit to cross the boundary. If space remained that they could repeat this process along another edge, they did so, often orienting the area unit in a different direction (see Figure 3). Then, they filled in the remainder of the Funky Shape using partial area units. In their written explanations, the PSTs reported that the squares, rectangles, and trapezoids "fit together". However, their desires to align the area units with the boundary of the Funky Shape and to keep the area units within the Funky Shape appeared to inhibit them from orienting each area unit in the same direction throughout. Failing to maintain the orientation of an area unit introduces at least two dilemmas: gaps or overlaps in the middle of the measured region and a lack of partitioning the region as an array of squares. Nearly all groups commented that a disadvantage of the tessellating area units was that they did not line up with the rounded edge of the Funky Shape. Only one group commented that it was hard to quantify partial units of trapezoids, and another group commented it was easier to quantity partial units of squares.

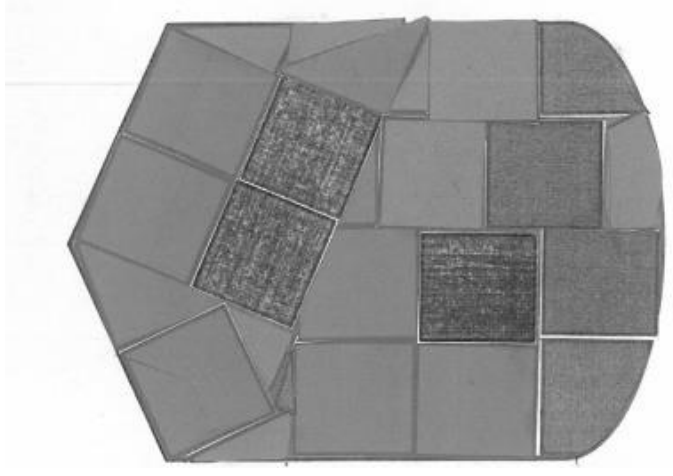

Figure 3. Example of the PSTs' tendencies to use different orientations of an area unit

The whole-class discussion began when I asked Anita (a pseudonym, as are all names) to describe their group discussion. She shared that the peanuts and circles were hard to use as area units because they did not have straight edges. I then added that if area units have straight edges, then they often line up next to each other whereas circles and peanuts leave gaps when placed side by side. I explained, "Tessellating is when you can repeat a shape next to itself over and over and it covers and doesn't leave any gaps or have any overlaps." I then asked the class, "Of the shapes that are left, which ones tessellate?" For the next several minutes, I engaged the PSTs in making drawings to illustrate how rectangles, trapezoids, and squares tessellate. I then asked the PSTs to discuss, "Are rectangles, squares, and trapezoids equally as good for area units or did you have preferences for some?" When I called on Rosina, she explained that "the rectangles and trapezoids worked best for this particular shape (emphasis added)." Thus, I asked the PSTs, "So, would it be helpful to pick a shape for an area unit based on the shape of the object I am measuring?" After time to discuss in their groups, Zach explained that "squares might be easier because if squares you can cut it in halves, quarters, etc." I then asked, "So, you're saying squares regardless of what your shape looks like?" He responded, "Yes, because it's easier to break up into smaller pieces because like with the trapezoid when I cut it, I wasn't sure if it was a half or a third." I then noticed that class time was running out, so I explained, "Beyond this class, have you ever been asked to measure area in trapezoids before? Guess what we conventionally use?" The PSTs collectively responded, "squares”. I concluded the discussion as follows, "And we use squares because squares are uniform, the same length on all sides and because of that uniformity these are at least the easiest shape to take partial units of."

On \#1 of the formative assessment, all PSTs explained that circle area units leave gaps between repetitions. On \#2, 25 PSTs explained or demonstrated that squares "fit together". Nineteen of these PSTs demonstrated how the squares tessellate and kept the squares oriented in the same direction. In contrast, five PSTs demonstrated how the squares may fit together, but oriented the squares in different directions to align with the edges of the pentagon. Twenty PSTs demonstrated evidence of the need to use partial units of squares for complete coverage; however, some PSTs still revealed resemblance and boundedness issues. For example, four PSTs expressed preferences for area units that would align with the edges of the pentagon (such as a triangle), and four other PSTs used only one big square to fill as much of the pentagon as possible without going over the boundary. Finally, only seven PSTs commented on \#1 or \#2 that it is easier to quantify partial units of squares than for other tessellating shapes.

\section{Steps Three and Four: Evaluate and Revise the Learning Goals, Hypotheses, and Lesson}

To evaluate my hypotheses for supporting the PSTs in attaining the learning goals, I returned to my written summaries of the PSTs' mathematical understandings on the class activity, during the whole-class discussion, and on the Formative Assessment. 
First, I noted instances in which the learning goals were attained by the PSTs and returned to the hypotheses and lesson plans to identify which lesson activities appeared to engender such understandings. Next, I noted instances in which the learning goals were not attained by the PSTs or misconceptions remained. Then, I again turned back to the hypotheses and lesson plans to identify how the lesson activities may have failed to address such issues. These issues pointed to instructional improvements. Ultimately, I gathered my notes on the impact of the instruction and my instructional adjustments and prepared an explanation of whether and how the hypotheses and lesson plans supported the learning goals.

At the end of the first-cycle lesson, all PSTs recognized that area units need to cover without gaps or overlaps the region to be measured and that to do so, such area units must "fit together". I concluded that having the PSTs measure the same irregular region with different-shaped area units enabled the PSTs to recognize this need. Furthermore, all PSTs understood that circles are not a viable area unit because gaps remain. Thus, engaging the PSTs in a discussion about measuring the Funky Shape with various area units assisted the PSTs in relinquishing resemblance preferences for area units with curved regions. However, shortcomings in the PSTs' understandings remained. Only $2 / 3$ of the PSTs oriented an area unit in the same direction when covering a region, only $2 / 3$ extended the area unit over the boundary and used partial units accordingly, only seven PSTs argued that it is easiest to quantify partial units of squares, and eight PSTs still demonstrated resemblance preferences with angled regions.

As part of the instructional analysis, I was shocked to find how often the PSTs changed the orientation of an area unit on the class activity and the formative assessment. This revealed the PSTs may have had little to no experience with measuring the area of an irregular region using an area unit tessellated with the same orientation. Furthermore, many of the PSTs did not appear to appreciate that partial units of squares are easier to quantify than partial units of other tessellating area units. Thus, I theorized that if the PSTs had the opportunity to measure an irregular region using tessellated versions of each area unit, they would come to better appreciate the ease of quantifying partial units of squares. Thus, my main instructional revision was to add a follow-up activity in which the PSTs would use transparency grids of tessellated shapes (e.g., a grid of rectangles all tessellated with the same orientation and similar grids for trapezoids, triangles, and squares) to lay over and measure the area of the Funky Shape. Upon trying to determine an area measure for the Funky Shape, I expected that the PSTs would encounter the challenges of quantifing partial units and realize it is easiest to quantify partial units of squares.

\section{SECOND CYCLE OF THE LESSON EXPERIMENT}

\section{Step One: Learning Goals, Hypotheses, and Lesson Planning}

My analyses of the PSTs' thinking during the first cycle led me to more clearly articulate my learning goals, resulting in the following learning goals for the second cycle:

1. Area units need to cover the region without gaps or overlaps.

2. Area units should tessellate the plane, including a.) fitting together without gaps, and b.) extending in the same orientation to cover the plane.

3. When area units extend over the boundary of the region, we use partial area units to determine the area measure.

4. We use square area units in part due to the ease of quantifying partial units of squares.

5. We use square area units despite the shape of the region to be measured.

My first hypothesis was asking the PSTs to complete the class activity would enable the PSTs to attain learning goals \#1 and \#2a. My second hypothesis was that the whole-class discussion about the class activity paired with the tessellated grids activity would help the PSTs attain the remaining learning goals (i.e., \#2b and \#3-5).

For the second-cycle lesson, 32 PSTs worked in groups on the class activity, with one slight change. In the first cycle, the PSTs had used paper cut-outs of the area units, spending a lot of time cutting and taping the cut-outs onto the Funky Shape. For the second cycle, I gave the PSTs manipulatives for the various area units, hoping that placing the manipulatives on the Funky Shape would proceed more quickly. As such, the area units changed to triangles, hexagons, circles, rhombuses, shells (of various sizes and shapes), trapezoids, squares, and kidney bean counters. After the class activity, we engaged in a whole-class discussion, identifying which area units tessellate. I then provided each group with the tessellated grids and directed them to re-measure the area of the Funky Shape. We engaged in a discussion about which tessellated area units were more efficient and accurate. We concluded with 31 of the 32 PSTs taking the formative assessment (one PST was absent).

\section{Step Two: Evidence of PSTs' Thinking}

For evidence of the PSTs' thinking during and after the second-cycle lesson, I again collected each group's written work on the class activity, video-taped the whole-class discussion, and collected from 31 of the 32 PSTs the same formative assessment. My analysis of the data again consisted of two phases, first determining the extent to which the learning goals were achieved (step 2 of a lesson experiment) and then evaluating the hypotheses and instruction for how they supported or hindered the learning goals (steps 3 and 4). I conducted these analyses in the same fashion as completed during the first cycle.

The PSTs' thinking from the second-cycle class activity mirrored those from the first cycle. For the non-tessellating area units (circles, shells, and kidney bean counters), all the groups randomly placed the area units as close together as possible over the Funky Shape, keeping the area units within the boundary. For the tessellating area units (hexagon, rhombus, square, rectangle, and trapezoid), the PSTs again aligned the area units along the boundary of the Funky Shape, often orienting the area unit in different directions, leaving gaps between repetitions of the area unit and failing to partition the region as an array. To determine 
the area measurement with both the non-tessellating and tessellating area units, the PSTs added the number of whole area units and their mental quantifications of the partial units needed to fill in the gaps.

When evaluating the various area units, the PSTs acknowledged some important features but were still guided by resemblance and boundedness preferences. For the shells, seven of the eight groups recognized that they were different shapes and sizes, leading to inconsistent measurements. For the circles and kidney beans, all but one group commented that these shapes leave gaps between their repetitions. For the tessellating area units, every group commented with at least one unit that they "fit together". Three groups considered the ease of quantifying partial units, one group noting the ease of determining half of a hexagon, one group commenting "squares are easy to estimate", and one group acknowledging the "need for fractions" because rhombuses do not cover all of the Funky Shape. All groups exhibited resemblance and boundedness with at least one of the area units. Their comments focused on whether particular area units lined up with the straight, curved, and angled edges of the Funky Shape.

For the first few minutes of the whole-class discussion, we considered the trade-offs between larger and smaller area units, concluding that larger area units require less counting but may be less accurate. Our class discussion then turned to considering the shells, and Lisa explained, "they are not accurate because they are all different sizes. The squares are all the same size so you can say what the area is." Sherri then shared that they could line up the squares along the side and then across a top row rather than completely filling in the area with squares. As class time ran out, I concluded, "So you could use something like grids, like rows and columns, to make it a little faster to count rather than just having them randomly dispersed." At our next class, I began by asking whether any of the other shapes had drawbacks as area units. Emma shared that kidney beans "left like little spaces that made it hard to estimate how much." After collectively agreeing that circles leave gaps as well, I asked, "So, now we've got triangles, hexagons, rhombuses, trapezoids, and squares left. Did they have the nice property that they can fit together? Yes, they all tessellate on their own. Tessellate means each shape can fit together without gaps and without overlaps to completely cover a two-dimensional region." I then asked the PSTs to discuss at their tables whether they thought these remaining five shapes worked equally well as an area unit. After a few minutes, I told them that I had overheads with tessellated grids for the triangles, rhombuses, hexagons, squares, and trapezoids. I directed the PSTs to re-measure the Funky Shape with the grids.

After approximately 10 minutes, Mary explained, "Well, the rhombuses were really difficult to line up the shape in a way that could either split it in half or make the units easier to count." I then asked the PSTs whether any of the area units they used exactly lined up with all the edges of the Funky Shape, to which they answered "no." Then, illustrating with the rhombus grid on the document camera, I continued, "With the rhombuses, ... even if I line up with one edge, somewhere else it isn't going to line up. . . . You're gonna have to break some of those area units up. I call those 'partial area units'. Mary, you were saying how it was kind of hard around the edges?" Mary answered, "Yeah, because we lined up one edge but on the other edge, it was somewhere in between." I said, "Yeah, like this one right here. (I shaded in a partial unit on the rhombus grid.) If you were having to be real precise, how much of a rhombus is that? $5 / 6$ ? $7 / 8$ ? So, taking these partial units of a rhombus was kind of hard." Upon asking Mary if any of the area units worked better, she answered, "The squares were much easier to line up." I put the square tessellation on the document camera and explained, "Would you say in general that when you were using the squares it was a little easier to tell on those partial units how much was left? ... Guess what we use for the standard shape for an area unit?" PSTs answered, "squares". I continued explaining, "Squares are not the only thing that tessellate. ... But it turns out squares are convenient because they are easiest to take a partial unit of."

I then asked, "Last class, there was also the idea that it [the square] doesn't line up with the curved edge. ... Maybe squares are really good most of the time but maybe sometimes I should pick a different area unit depending on the shape of what I'm measuring?" After a few minutes, Jill explained that she could never recall when an area measurement was presented in anything but square units, reiterated the need for area units to tessellate, and concluded "with the squares you can easily see the fractional pieces." I then summarized, "We want to make things line up. Do you remember when you were younger and you were doing puzzles where you had to put some shapes on top of the other shapes? And you had to cover it exactly? I think this desire comes from that." I concluded, "So, our point from earlier about the squares didn't line up with the curved part of the Funky Shape, that's true and it is a difficulty, but it doesn't mean that we don't use squares. ... Regardless of what you're measuring, the fallback is always squares. To measure area, we count the number of square units that cover the two-dimensional region."

On \#1 from the formative assessment, 30 of the PSTs explained that circles leave gaps between their repetitions. On \#2, 26 PSTs included a drawing with squares tessellated in the same direction to cover the provided region. Overall, 21 PSTs noted the ease of partial units with squares. Six other PSTs utilized partial units of squares but did not explicitly comment that using partial units is easier with squares. Only two PSTs revealed resemblance and boundedness preferences. On \#2, one PST hinted at orienting squares in different orientations along the edges of the pentagon, and another PST revealed a desire to use one big square to cover the pentagon. Table 1 summarizes the improvement in the PSTs' performance between the first and second cycles.

Table 1. PSTs' understandings on the formative assessment from the first to the second cycle

\begin{tabular}{|c|c|c|}
\hline Learning Goal & First Cycle & Second Cycle \\
\hline 1. Area units need to cover the region without gaps or overlaps & All understood & All understood \\
\hline $\begin{array}{l}\text { 2. Area units should tessellate the plane: (i) fit together without gaps and } \\
\text { (ii) extend in the same orientation }\end{array}$ & $\begin{array}{l}\text { (i) All understood } \\
\text { (ii) } 61 \%(19 / 31)\end{array}$ & $\begin{array}{l}\text { (i) All understood } \\
\text { (ii) } 84 \%(26 / 31)\end{array}$ \\
\hline 3. Partial area units are used when units cross the boundary of the region & $65 \%(20 / 31)$ understood & $87 \%(27 / 31)$ understood \\
\hline 4. We use square area units due to the ease of quantifying partial squares & $23 \%(7 / 31)$ understood & $68 \%(21 / 31)$ understood \\
\hline 5. We use square area units despite the shape of the region to be measured & $\begin{array}{l}26 \%(8 / 31) \text { revealed resemblance } \\
\text { preferences }\end{array}$ & $\begin{array}{l}6 \%(2 / 31) \text { revealed } \\
\text { resemblance issues }\end{array}$ \\
\hline
\end{tabular}




\section{Steps Three and Four: Evaluate and Revise the Learning Goals, Hypotheses, and Lesson}

To evaluate my hypotheses for supporting the PSTs in attaining the learning goals during the second cycle, I utilized a similar process to that in the first cycle of comparing the learning goals and hypotheses with the results from the class activity, wholeclass discussion, and formative assessment. My evaluation of the second-cycle class activity revealed two affordances and one disadvantage. First, the class activity attained the objectives of the first hypothesis. Second, as the physical manipulatives for the area units could not be cut, the PSTs were more compelled to place the area units as close together as possible to reduce gaps. Thus, the PSTs realized on their own how the area units tessellated. A drawback of the class activity was its length, so I propose eliminating one of the tessellating area units and the circle or kidney bean area unit.

As predicted by the second hypothesis and evidenced on the formative assessment, the whole-class discussion and the tessellated grids activity enabled the PSTs to attain the remaining learning goals for the lesson (\#2b, \#3-5). However, my evaluation of the whole-class discussion and the tessellated grids activity revealed two shortcomings. First, I failed in real-time to fully understand that Sherri was alluding to using length $x$ width to calculate the number of squares, which is another advantage of square area units. Thus, I recommend adding the following learning goal: Square units partition the measured region as an array, so one can use length $\times$ width for any rectangular portions. Second, I found that I did too much of the explaining during the discussion. For future lessons, I would have several PSTs demonstrate measuring the area with the tessellated grids, including how they quantified the partial units. This would enable me to facilitate more numerical comparisons of the PSTs' area measurements, with attention to more variability with the non-square area units. With regard to the boundedness preferences, I would ask the PSTs for their ideas. "Do you think elementary students will want to align the area units with the edge of the measured region? Why? Where do you think such boundedness preferences might arise? How might they be addressed in the classroom?" Collectively, these revisions may increase the opportunity for explanations about quantifying partial units and pedagogical implications of boundedness to be supplied by the PSTs.

\section{DISCUSSION}

One purpose of this paper was to present classroom lessons learned about supporting PSTs with understanding area measurement. As such, the paper described two cycles of a lesson experiment conducted in a mathematics class for elementary PSTs. Across the two cycles, the lesson experiment process enabled me to elicit the mathematical understandings of PSTs, to refine my learning goals and hypotheses for how instruction may support such goals, and to revise the lesson accordingly. With the second cycle, more PSTs attained more of the learning goals. In this process, I identified various factors that affected the PSTs' learning about area units. I learned that PSTs quickly appreciate that non-tessellating area units leave gaps and therefore the best shapes for area units must fit together to cover a region. I recognized common limitations in the PSTs' thinking about area units, including boundedness and resemblance preferences and tendencies to orient a given area unit in different directions while covering a region. Finally, I came to appreciate a potential learning trajectory for helping PSTs effectively select area units: cover an irregular region with variously shaped area units, compare and contrast such units, and then investigate measuring area with tessellated grids. In sum, the lesson experiment process not only enhanced my knowledge of PSTs' mathematical understandings, but it enhanced my ability to respond to such understandings in a tangible way and improve my general teaching practice. In particular, the two cycles enhanced my ability to actively engage the PSTs in making sense of mathematical ideas during their own mathematical activity, rather than the PSTs simply adopting my thinking or that of their peers from the whole class discussions (Simon, 2011).

It is important to acknowledge possible limitations of the lesson experiment. First, the data from the class activity as well as the whole class discussion in both cycles was limited to group data and those students called upon during the discussions. Gathering data from all individuals during the class activity or whole class discussion may have led to additional information about the PSTs' thinking about area units. Second, the PSTs from these two classes may have had background experiences leading to understandings that may be different than those of PSTs from more diverse geographical regions. Third, the format of the class activity or the formative assessment may have indirectly contributed to the PSTs' understandings. Finally, due to contextual circumstances, I conducted the lesson experiment on my own. Collaboration with fellow mathematics instructors or teacher educators may have led to further insights or instructional revisions. Conducting two cycles of the lesson experiment however may have lessened the impacts of these limitations.

As described above in the review of PSTs' understandings and shortcomings in area measurement, PSTs often reveal confusions about area units (Baturo \& Nason, 1996; Simon \& Blume, 1994; Tierney et al., 1990), including failing to appreciate the affordances of using unit squares for area units (Chamberlin \& Candelaria, 2018). This paper describes a lesson approach that may be used to address such shortcomings as part of PSTs' undergraduate mathematics coursework. In the lesson, I strove to mirror the techniques used by other instructors to enhance PSTs' area understandings (Runnalls \& Hong, 2019; Simon \& Blume, 1994; Tierney et al., 1990). In particular, I attempted to emphasize area from a conceptual standpoint with non-formulaic activities, to engage the PSTs in meaningful discussions, and to continually assess and respond to the PSTs' thinking in lesson activities. The lesson experiment process facilitated my efforts in all three of these areas. As such, my secondary purpose with this paper is to share the lesson experiment process with fellow mathematics instructors and teacher educators in various settings and contexts.

Mathematics teachers, instructors, and teacher educators are often pressed for time. Lesson experiments provide a feasible means for improved outcomes for our students as well as opportunities for reflection and learning about our own professional practices of teaching. The feasibility of lesson experiments arises from their manageable size - focusing on a single task, lesson, or short sequence of lessons. In addition, they may be undertaken by an individual instructor or in collaboration with others. The 
empirical data collected and analyzed moves reflection on teaching from an informal process to a rigorous and at times researchintensive activity. Such activity supports the multiple roles of mathematics instructors and teacher educators as teachers, researchers, and life-long learners. Finally, lesson experiments are amenable to different topics with different audiences, whether mathematical goals, pedagogical goals, or some combination thereof. Mathematics instructors or teacher educators may even model the use of lesson experiments in their classes for PSTs to learn how to conduct them in their own future teaching assignments.

For those interested in undertaking a lesson experiment, I offer a few suggestions. First, consult as desired the references cited here for additional guidance and detail about lesson experiments (Hiebert et al., 2003, 2007). Then, begin the process individually or in collaboration with others, e.g., fellow colleagues, graduate students, researchers, etc. Try to plan for at least two cycles if possible; cycles enable testing whether changes are improvements or just changes (Jansen et al., 2009). Ultimately, the best way to learn about lesson experiments is just to complete one (Phelps \& Spitzer, 2012). Even when I was not sure if I was following the lesson experiment protocol correctly, I was still amazed by the detail and depth I learned about the PSTs' thinking and associated instructional factors. Finally, capture your reflections and revisions to share and disseminate with other instructors and educators. Such revised lesson plans represent the exact type of visible, tangible, and changeable products called for by Hiebert and Morris (2009) to contribute to the shared knowledge base for mathematics teachers, instructors, and teacher educators. In sum, lesson experiments have the potential to lead not only to enhanced mathematical learning for students and PSTs, but for mathematics teachers, instructors, and teacher educators as well.

Funding: No funding source is reported for this study.

Declaration of interest: No conflict of interest is declared by author.

\section{REFERENCES}

Battista, M. T. (2003). Understanding students' thinking about area and volume measurement. In D. H. Clements (Ed.), Learning and teaching measurement (2003 yearbook) (pp. 122-142). National Council of Teachers of Mathematics.

Baturo, A., \& Nason, R. (1996). Student teachers' subject matter knowledge within the domain of area measurement. Educational Studies in Mathematics, 31, 235-268. https://doi.org/10.1007/BF00376322

Bilir, C. K. (2018). Pre-service teachers' understanding the measurement of the area of rectangles [Doctoral dissertation, Purdue University]. https://search.proquest.com/docview/2051466222

Berenson, S., van der Valk, T., Oldham, E., Runesson, U., Moreira, C. Q., \& Broekman, H. (1997). An international study to investigate prospective teachers' content knowledge of the area concept. European Journal of Teacher Education, 20(2), 137-150. https://doi.org/10.1080/0261976970200203

Browning, C., Edson, A. J., Kimani, P. M., \& Aslan-Tutak, F. (2014). Mathematical content knowledge for teaching elementary mathematics: A focus on geometry and measurement. The Mathematics Enthusiast, 11(2), 333-384.

Chamberlin, M. T., \& Candelaria, M. S. (2018). Learning from teaching teachers: A lesson experiment in area and volume with prospective teachers. Mathematics Teacher Education and Development, 20(1), 86-111.

Conference Board of the Mathematical Sciences (CBMS). (2012). The mathematical education of teachers/l. Mathematical Association of America in cooperation with the American Mathematical Society. http://www.cbmsweb.org/archive/MET2/met2.pdf

Hiebert, J., \& Morris, A. (2009). Building a knowledge base for teacher education: An experience in K-8 mathematics teacher preparation. The Elementary School Journal, 109(5), 475-490. https://doi.org/10.1086/596997

Hiebert, J., Morris, A., K., Berk, D., \& Jansen, A. (2007). Preparing teachers to learn from teaching. Journal of Teacher Education, 58(1), 47-61. https://doi.org/10.1177/0022487106295726

Hiebert, J., Morris, A. K., \& Glass, B. (2003). Learning to learn to teach: An "experiment" model for teaching and teacher preparation in mathematics. Journal of Mathematics Teacher Education, 6, 201-222. https://doi.org/10.1023/A:1025162108648

Jansen, A., Bartell, T., \& Berk, D. (2009). The role of learning goals in building a knowledge base for elementary mathematics teacher education. The Elementary School Journal, 109(5), 525-536. https://doi.org/10.1086/597000

Lehrer, R. (2003). Developing understanding of measurement. In J. Kilpatrick, W. G. Martin, \& D. Schifter (Eds.), A research companion to principles and standards for school mathematics (pp. 179-192). National Council of Teachers of Mathematics.

Lehrer, R., Jacobson, C., Thoyre, G., Kemeny, V., Strom, D., Horvath, J., Grance, S., \& Koehler, M. (1998a). Developing understanding of geometry and space in the primary grades. In R. Lehrer \& D. Chazan (Eds.), Designing learning environments for developing understanding of geometry and space (pp. 169-200). Lawrence-Erlbaum.

Lehrer, R., Jaslow, L., \& Curtis, C. (2003). Developing an understanding of measurement in the elementary grades. In D. H. Clements (Ed.), Learning and teaching measurement (2003 yearbook) (pp. 100-121). National Council of Teachers of Mathematics.

Lehrer, R., Jenkins, M., \& Osana, H. (1998b). Longitudinal study of children's reasoning about space and geometry. In R. Lehrer \& D. Chazan (Eds.), Designing learning environments for developing understanding of geometry and space (pp. 137-167). Lawrence-Erlbaum.

Livy, S., Muir, T., \& Maher, N. (2012). How do they measure up? Primary pre-service teachers' mathematical knowledge of area and perimeter. Mathematics Teacher Education and Development, 14(2), 91-112. 
National Governors Association Center for Best Practices (NGA Center) \& Council of Chief State School Officers (CCSSO). (2010). Common core state standards for mathematics. http://www.corestandards.org/

Phelps, C. M., \& Spitzer, S. M. (2012). Systematically improving lessons in teacher education: What's good for prospective teachers is good for teacher educators. The Teacher Educator, 47(4), 328-347. https://doi.org/10.1080/08878730.2012.707759

Reinke, K. S. (1997). Area and perimeter: Preservice teachers' confusion. School Science and Mathematics, 97(2), 75-77. https://doi.org/10.1111/j.1949-8594.1997.tb17346.x

Reynolds, A., \& Wheatley, G. H. (1996). Elementary students' construction and coordination of units in an area setting. Journal for Research in Mathematics Education, 27, 564-581. https://doi.org/10.2307/749848

Runnalls, C., \& Hong, D. S. (2019). "Well, they understand the concept of area”: Pre-service teachers' responses to student area misconceptions. Mathematics Education Research Journal, 32, 629-651. https://doi.org/10.1007/s13394-019-00274-1

Sarama, J., \& Clements, D. H. (2009). Early childhood mathematics education research: Learning trajectories for young children. Routledge. https://doi.org/10.4324/9780203883785

Simon, M. A. (2011). Studying mathematics conceptual learning: Student learning through their mathematical activity. In L. R. Wiest \& T. Lamberg (Eds.), Proceedings of the $33^{\text {rd }}$ annual meeting of the north American chapter of the international group for the psychology of mathematics education (pp. 31-43). http://www.pmena.org/pmenaproceedings/PMENA\%2033\%202011\%20Proceedings.pdf

Simon, M. A., \& Blume, G. W. (1994). Building and understanding multiplicative relationships: A study of prospective elementary teachers. Journal for Research in Mathematics Education, 25(5), 472-494. https://doi.org/10.2307/749486

Sowder, J., Sowder, L., \& Nickerson, S. (2014). Reconceptualizing mathematics for elementary school teachers. Freeman.

Stephan, M., \& Clements, D. H. (2003). Linear and area measurement in prekindergarten to grade 2. In D. H. Clements (Ed.), Learning and teaching measurement (2003 yearbook) (pp. 3-16). National Council of Teachers of Mathematics.

Strauss, A., \& Corbin, J. (1998). Basics of qualitative research: Techniques and procedures for developing grounded theory (2nd ed.). SAGE.

Tatto, M. T., Schwille, J., Senk, S. L., Ingvarson, L., Rowley, G., Peck, P., Bankow, K., Rodriguez, M., \& Reckase, M. (2012). Policy, practice, and readiness to teach primary and secondary mathematics in 17 countries: Findings from the IEA Teacher Education and Development Study in Mathematics (TEDS-M). International Association for the Evaluation of Educational Achievement (IEA).

Tierney, C., Boyd, C., \& Davis, G. (1990). Prospective primary teachers' conceptions of area. In G. Booker, P. Cobb, \& T. D. Mendecuti (Eds.), Proceedings of the 14th Annual Conference of the International Group for the Psychology of Mathematics Education (pp. 307-315). Mexico: International Group for the Psychology of Mathematics Education.

Van de Walle, J. A. (2007). Elementary and middle school mathematics: Teaching developmentally (6th ed.). Pearson. 